\title{
FURTHER EXPLORATIONS OF SUPERNATURALISM ABOUT MEANING IN LIFE: REPLY TO COTTINGHAM, GOETZ, GOLDSCHMIDT, JECH AND WIELENBERG
}

\section{THADDEUS METZ}

\author{
University of Johannesburg
}

\section{REVISITING SUPERNATURALISM}

It is an honour for the editors of the European Journal for Philosophy of Religion, Janusz Salamon and Yujin Nagasawa, to have devoted a special issue of it to my book, Meaning in Life: An Analytic Study (Metz 2013a), and for them to have assembled such a distinguished group of commentators. They have made welcome, thoughtful contributions about several key claims made in the book. I am grateful to John Cottingham, Stewart Goetz, Tyron Goldschmidt, Alexander Jech and Erik Wielenberg for having taken the time to share their expertise and insight with me and the rest of the field.

In Meaning in Life, I critically engage with Anglo-American theoretical analyses of what, if anything, would make a human person's life meaningful, setting aside the more holist or cosmic questions of what the point of the human race is or why there is a physical universe. I maintain that the question of what could confer meaning on an individual's life is roughly equivalent to asking what beyond one's own pleasure most merits pursuit, how to transcend one's animal self, and what about one's life merits great esteem or admiration. I group theoretical answers to these questions under two major headings, supernaturalism and naturalism, where the former is the view that God or a soul as typically conceived in the monotheist tradition is necessary for meaning in a life. ${ }^{1}$

\footnotetext{
${ }^{1}$ Cottingham does not like the term 'supernatural', as it suggests to him that there is not meaning to be found in nature (2016: 47-50). However, that is clearly not intended
} 
I provide new arguments against not only the specific supernaturalist view that meaning is constituted by fulfilling God's purpose, but also supernaturalism as a general category, which I contend is motivated at bottom by the implausible view that engagement with perfection is essential to meaning. After having sought to provide sufficient reason to reject this perfection thesis and its supernaturalist offshoots, I advance a new naturalist view, the 'fundamentality theory', which I contend is more attractive than previous versions of naturalism from the literature. ${ }^{2}$

There are several respects in which my interlocutors would like to convert me to the view that God or a soul is necessary for meaning in life, or at least maintain that I have not provided sufficient reason to reject it. In the following I reply to them, grouping their discussions thematically, according to four major kinds of criticism they make.

To begin, some of the contributors question my methodology. In the book, I treat the question of life's meaning as a theoretical matter, and evaluate general principles about what all meaningful conditions have in common as distinct from meaningless ones mainly by appealing to intuitions, particular judgments of what is meaningful and what is not. Goldschmidt and Jech doubt that this strategy gets me very far (section II).

Next, a number of the commentators seek to defend the supernaturalist view that meaning is constituted by fulfilling God's purpose from the objection I make to it (section III). I contend that in order for God to be necessary to confer meaning on our lives, God would have to be qualitatively different from and higher than anything that could exist in the physical world, that this means that God would have to be a person who has properties such as simplicity and atemporality, and that these properties are incompatible with purposive agency, at least as typically conceived by monotheists. Goetz, Goldschmidt and Wielenberg contend that this argument fails to convince.

I then address the way that my interlocutors seek to defend supernaturalism as such from the 'incoherence argument' I mount against it (section IV). I contend that most inclined towards supernaturalism

by those using the term, and probably does not even have that connotation to them; for the entire debate is about whether meaning in this, earthly life would exist were there not something beyond it in another, higher dimension, something supra natural.

${ }^{2}$ For a somewhat longer summary of the book's key claims, see 'Précis of Meaning in Life: An Analytic Study', published elsewhere in this issue of the European Journal for Philosophy of Religion. 
would hold a collection of claims that contradict each other if they were to do so. Roughly, on the one hand, most supernaturalists claim to know that some lives have meaning in them, but, on the other, they claim not to know that anything supernatural actually exists, making it incoherent to claim to know that meaning logically depends on the supernatural. Supernaturalists often have faith in a spiritual realm, but that is of course not knowledge of its existence, which most implicitly maintain they have about the presence of meaning in people's lives. Cottingham and Wielenberg take issue with this argument.

Finally, I consider the way that critics have responded to the fundamentality theory, my favoured account of what makes a life meaningful (section V). According to it, a life is particularly meaningful insofar as it exercises reason in a robust, sophisticated way and orients it towards basic conditions of human existence, ones that are largely responsible for or explain much else about it. I aim to show that the exemplars of meaning in people's lives, namely, 'the good' (morality, beneficence), 'the true' (enquiry, wisdom) and 'the beautiful' (creativity, art), are best captured by a principle that prescribes positively contouring one's intelligence towards fundamental aspects of human life. Here, Goetz and Goldschmidt are not persuaded.

Ever since I began thinking about what might make a life meaningful, I have been drawn towards religious or spiritual views but never believed them. I have wanted both supernaturalism and theism to be true, so that God and a soul would be necessary for meaning and would be known to exist. However, I have not been able to bring myself to think that either of these claims is true. At the end of the book I note this discrepancy between the conative and cognitive parts of my self, indicating that while I wish I were fulfilling a purpose God had assigned me and were destined to live well forever consequent to having done so, I do not believe that such would be necessary for my life to be meaningful (2013a: 247-248; see also 127-128). It is uncomfortable having to revisit this tension, which Goetz and Jech both press in their contributions, but, then, growth is invariably accompanied by discomfort.

Upon exploring supernaturalism further in replying to my esteemed interlocutors, I do not find the tension dissolved. I continue to maintain that a life could be meaningful if only the physical universe exists, and I continue to hope (which is distinct from expecting) that there is more to life than merely what can be found in the physical universe. One way to account for this discrepancy, which I toyed with in the book (2013a: 
242-247), is that human values are distinct from human idealizations. However, another potential explanation, which I did not discuss in the book (but cf. 2013a: 159-160) and intend to explore in future work, is that there are two dimensions or kinds of meaning in life, such that a deeper or higher (depending on your preferred metaphor of verticality) sort requires perfection. I am convinced that, if there is a kernel of truth in supernaturalism, it lies in articulating, defending and applying this distinction between types of meaning in a life (for some recent starts, see Metz 2015a: 239-240, 2016; Swinburne 2016).

\section{HOW TO ADDRESS ISSUES OF MEANING}

The method used to support a conclusion about what makes a life meaningful in my book is new in one respect, but not in another. It is not in that it is (intended to be) identical in form to the standard approach taken by analytic philosophers when constructing theories of the nature of well-being, right action, epistemic justification, personal identity, free will and much else. Just as the moral philosopher evaluates a general principle of what distinguishes permissible acts from impermissible ones by appealing to particular cases that are less controversial than the principle being evaluated, i.e., to 'intuitions', so I do the same when it comes to theories of meaning. I evaluate them, and defend my favoured view, principally by considering the extent to which a given theory plausibly entails and powerfully explains less contested judgments about what does and does not confer meaning on a life.

To the extent that there is novelty in the book's method, it is that I apply this kind of argumentative strategy with some rigour to the topic of what makes a life matter. I point out that the field has for over 100 years tended to take the good, the true and the beautiful as quintessential instances of meaningfulness, and so I take intuitions about them to constitute fair, common ground by which to evaluate competing theoretical accounts of what confers meaning on a life. Both supernaturalists and naturalists have held that there can be substantial meaning in, for instance, helping other people, discovering facts about the world and creating artworks. I run through about two dozen different general principles in search of the one that does the best job of accounting for such particular judgments, with recurrent mention of the intuitively meaningful accomplishments of Mother Teresa, Nelson Mandela, Charles Darwin, Albert Einstein, Vincent van Gogh and Fyodor Dostoyevsky. 
Jech contends that this method is inappropriate. According to him, intuitions are epistemically insecure, and, because of that, they are ineffective at providing reason to doubt supernaturalism. The 'erosion of trust in such intuitions', he says, means that they cannot be invoked to doubt any 'systematically anti-intuitive views' that supernaturalists might have $(2016: 15,16)$.

Jech advances these claims consequent to an eloquent, revealing and compelling analysis of Pascal's Pensées. Indeed, I submit that Jech's beautiful exposition of Pascal has conferred some meaning on his life (even if there exists neither God nor a soul!). According to his reading of Pascal, the only epistemic reasons we finite humans can ever access are incomplete and therefore shaky. They are bound to be, in Jech's terms, 'uncertain', 'arbitrary', 'groundless', 'accidental', 'a product of custom', 'variable' and 'contingent'. Alternately, they are not ones, again using Jech's words, 'whose denials are self-contradictory' or that 'contain the totality of knowledge at once' or that are grounded on an 'absolute perspective, where only such kinds of justification can satisfy the demands of rational enquiry. Supernaturalists ought therefore not be bothered if their views are shown to be counter-intuitive, and I ought not criticize them as such.

I do not take issue with Jech's account of Pascal, but rather with the implications he draws from it. First off, I suspect that Jech, and his Pascal, end up in self-refutation or self-stultification of some kind. On the one hand, they claim that all our beliefs are insufficiently justified by virtue of their arbitrariness, accidentalness and the like. On the other hand, they believe precisely that claim, they assert it as true and justified. Doing so means they implicitly either deem that belief (about the status of our beliefs) not to be arbitrary, accidental, etc., or think that the latter conditions do not undercut epistemic justification. Jech and Pascal both end up convinced about an awful lot about the human condition, and reasonably so by their own lights, despite the fact that what they are reasonably convinced about is that we cannot be reasonably convinced about much about the human condition. ${ }^{3}$

My second reply to Jech is that his and Pascal's standards for justified belief are much too high. The best way to see that, beyond the charge of self-refutation that I have just levelled, is to consider humanity's most

${ }^{3}$ Cf. my discussion of Sho Yamaguchi (2015), who contends that an appeal to intuition on my part lacks justificatory force, but whom I argue himself appeals to intuition in order to defend that contention, and probably does so unavoidably (Metz 2015a: 248-250). 
successful epistemic enterprise with respect to the nature of external reality, namely, contemporary science. Scientific claims are uncertain, they change over time, they are a product of particular histories and cultures, and all the rest. And, yet, for all we can tell, we do know that water is $\mathrm{H}_{2} \mathrm{O}$ and that the earth is round and not flat.

The success of science holds important lessons for the nature of epistemic justification, one of which is that certainty, absoluteness and the like are not necessary for it. Humans have not always employed chemical concepts. Only certain societies came up with these concepts. Their application to the nature of the world is only probabilistically accurate, and not certain. And, yet, they do ground knowledge: water really is $\mathrm{H}_{2} 0$.

My suggestion, following post-positivism in general and the Cornell realism of Richard Boyd, David Brink, Richard Miller and Nicholas Sturgeon in particular, is that beliefs about values can be justified in much the same way beliefs about reality can be (cf. Metz 2013a: 7, 91-96, 169-172). Concepts about meaning in life have not always been invoked by human beings. Only some societies have done so. And the evidence for their application will invariably be less than certain, a matter of probability. However, if beliefs about what exists can be justified in the face of these conditions, so, too, can beliefs about what is meaningful.

Like Jech, Goldschmidt provides reason to doubt the procedure of appealing to intuitions to defend a position, at least when it comes to the topic of meaning in life. I appreciate the transparency, sincerity and intellectual integrity evinced by Goldschmidt's discussion. With respect to several matters on which I pronounce having an intuition, he reports that he has none. And he notes that someone might have an intuition opposed to mine. Then the question becomes: what does this mean for justification?

Is non-purposive meaning logically possible? Suppose those who understand meaning in terms of purposiveness would contend that it is not. Are they then misunderstanding things? How can we tell? By checking what most people would make of the concept? But now we're into empirical questions. [...] I have no idea whether what most people think about such things should bear on the issue at all (Goldschmidt 2016: 21).

In making these points, Goldschmidt need not be read as rejecting the entire method of evaluating a general principle by appeal to less 
controversial particular judgments. Rather, he is sensibly read as suggesting that such a procedure fails to generate epistemic reason for belief when there are differences amongst the intuitions of interlocutors.

In reply, everything depends on the extent to which the intuitions of the interlocutors were authoritatively developed and how great the divergences are between those with the requisite credentials. ${ }^{4}$ First off, I take relevant intuitions to be ones that are substantially the product of careful and thorough consideration of the subject matter. If a deaf person lacks a sense of which music is beautiful, and if a janitor fails to judge that there is a proton spiralling off upon a collision of particles in a cloud chamber, their lack of intuition does not undercut the presence of one amongst composers and physicists. Some kind of expertise is needed.

Furthermore, the epistemic aim is not to find a theory that plausibly entails and explains all extant intuitions of a given interlocutor, even those of an expert, but is rather to find one that best accounts for intuitions held after the (usually lengthy) process of reflecting theoretically on them. For example, if someone who had thought for a while about issues of meaning judged Hitler's life to have been meaningful, then I would seek out some other, ideally stronger intuitions that he has, and make the case that they support a certain, more general principle (or cluster of them) that gives him reason to revise his Hitler intuition. Intuitions are not fixed; they are neither immune from cognitive influence, nor are they self-justifying à la foundationalism.

Secondly, I maintain that epistemic justification is going to track the degree of convergence amongst experts consequent to such a reflective process. Unanimity is not necessary. Instead what is appropriately sought and often achieved in contemporary science is a very large majority of experts agreeing that certain theoretical options are plausible or not, upon thorough investigation of the matter. Such substantial agreement but not full-blown consensus - is strong evidence for a view about the nature of the physical world, e.g., about quantum mechanics and the theory of human evolution. Where there is not much agreement amongst experts over time, then there is not much justification, at least of a sort that would give either enquirers epistemic reasons to change their minds or laypeople strong grounds to trust their testimony.

${ }^{4}$ This and the following couple paragraphs borrow some ideas and phrasings from Metz (2015a: 250). 
Supposing these reflections about the epistemic status of justification in science are plausible, I apply them to the context of enquiry into what makes a life meaningful. To begin, notice that Goldschmidt himself does not say that he has intuitions opposite to mine about meaningfulness. Rather, he usually claims that he has 'no intuitions' (2016: 21) and that his 'intuitions are silent' (2016: 21) about an array of issues. It therefore might be that Goldschmidt is too new to enquiry into life's meaning to count as an expert. He might need to reflect more on the matter to develop the ability to form judgments of particular cases.

Goldschmidt does proffer a case of someone else who has an intuition that differs from mine, specifically, someone who believes that nonpurposive meaning (meaning without having pursued, or at least brought about, an end) is logically impossible. Here, I would note that the mere possibility of someone with a different intuition is not epistemically relevant; actual difference of intuition amongst experts consequent to much theoretical discussion and other reflection is what should really give one pause. So, I would need to know whether someone familiar with the philosophy indeed maintains that the meaning of the phrase 'meaning in life' rules out the prospect of it inhering in non-purposive conditions.

Note that the mere fact that someone holds a general principle that has clear implications for particular cases does not mean that her judgments of the latter will in fact align with the former. Quite often those with different theoretical perspectives still share the same intuitions. Utilitarians about right action have taken seriously the barrage of deontological criticism mounted since the 1970s because they, too, have often enough had the same judgments of particular cases about when to harvest organs from innocents and when to sacrifice them to lions for the entertainment of spectators. So, in the present case, it could be that the adherent to purposive-only meaning at a theoretical level would in fact share my intuition about cases in which a non-purposive sort is available.

Suppose, now, there in fact exists an interlocutor of the sort Goldschmidt has in mind, roughly an expert who has an intuition opposed to mine. Then, it might be that she would have strong reason to change her mind if I were to point her to additional evidence, and there are times when I like to think that I can know that. Other times, I also believe that I can know that, even if this particular interlocutor would not come to share my view or have reason to do so, substantial 
convergence in my favour amongst experts exists or is forthcoming about a certain issue.

I of course have not provided reason to believe that Goldschmidt's particular counterexample about the concept of life's meaning is flawed. I have read him as proffering it mainly to illustrate a point about the justificatory force of intuitions, and hope I have said enough to clarify, and motivate, my view on that methodological issue.

\section{THE ROLE OF GOD'S PURPOSE IN A LIFE'S MEANING}

In my book, I work hard to give supernaturalist theories a fair shake. I use a large amount of space to defend them from objections that have been prominent in the literature on life's meaning. However, after showing that extant criticisms of supernaturalism can be rebutted without too much difficulty or at least with some conclusiveness, I aim to provide new criticisms that are not so easy to refute or to be sanguine about being able to refute. One target is the influential view that a life is meaningful only if, and perhaps just insofar as, it fulfils a purpose that God has assigned it. After arguing that this view can avoid the major objections that have been made to it (Metz 2013a: 98-106; see also Metz 2013b), I present a new objection (Metz 2013a: 106-118). ${ }^{5}$

Specifically, I maintain that in order for God to be necessary to confer meaning on our lives, God would have to be qualitatively different from and higher than anything that could exist in the physical world. For God to be essentially, perhaps solely, responsible for any meaning in our lives, God would have to have certain qualities that cannot be found in the natural world, these qualities must be lexically superior to any goods possible in a physical universe, and they must be what ground meaning in it. The best candidate for such qualities, I submit, is being a person who has properties such as simplicity and atemporality, which plausibly constitute certain superlative forms of unity and independence that confer meaning upon contouring one's life towards them. And these properties are probably incompatible with purposive agency, which appears to be essentially complex and temporal. If this argument is strong, or at least worth taking seriously, then, if one is drawn towards a God-centred account of meaning in life, one should develop and

${ }^{5}$ I first advanced this objection in Metz (2000), and then also defended it in Metz (2007), before the book appeared. For replies to this objection beyond those I address in this section, see Affolter (2007) and Poettcker (2015). 
consider a non-purposive version of it, and in the book I sketch what that might plausibly look like (Metz 2013a: 119-122).

Goldschmidt (2016: 24) and Wielenberg (2016: 30-31) reply mainly by pointing out that I have not undertaken the metaphysics needed to conclusively nail down this objection. They note that in the book I acknowledge there have been accounts of, say, how a simple and atemporal God could create a temporal universe despite it appearing to be the case that creation takes time and would involve complexity, but that I do not critically discuss them. They are correct about that, as Jason Poettcker is when he makes a similar point (2015: 190-192).

Here I echo my reply to Poettcker (drawing on Metz 2015a: 255-256). Basically, I am not a metaphysician, and also wanted to avoid intricate debates in metaphysics as much as I could in order to focus on the analytically under-explored issue of meaning (which I suggested on occasion at Metz 2013a: 111, 120, 134, 145-146, 170, 243). So, I drew upon traditional concerns in the literature about whether a radically other God could interact us in ways that adherents to purpose theory normally conceive, presenting a challenge to the latter to show that purposiveness can cohere with simplicity and atemporality (or that God need not have such properties in order to ground meaning). That is, I aimed to provide a new, difficult problem for purpose theory and 'the most significant' one (2013a: 113) that would provide reason to consider an alternative God-based theory of what would make life meaningful (2013a: 118).

Goetz goes a step farther and takes up this challenge (2016: 41-42). He replies not by trying to shift the metaphysical burden of proof back to me, but rather by trying to explain how a simple God could both act in time and for multiple purposes. Goetz interestingly draws an analogy between God and a soul, pointing out that a soul has often been conceived as a simple spiritual substance but nonetheless as existing in time and as pursuing several different ends. If a soul can be conceived to have all these properties at the same time, why not God?

The trouble with the analogy, I think, is that the kind of simplicity ascribed to God traditionally, and also plausibly when it comes to meaning, differs from the sort ascribed to a soul. Basically, the kind of simplicity that is compatible with being in time (and perhaps having multiple purposes) is not the sort that God must have in order to be qualitatively different from, and higher than, anything possible in nature and hence to be essential to ground meaning. If nothing in nature on its 
own could ground meaning, and God were necessary for it, then God would probably have to exhibit a unity and independence constituted by a simplicity that is atemporal. Recall, for instance, the 'feebleness of division' of which Plotinus speaks, which plausibly applies to a being with either spatial or temporal extension.

In sum, even if we can conceive of a simple God acting in time, that is not the sort of simple God that is plausibly required for meaning in life, because He would then be insufficiently above and beyond nature. Drawing on the perfect being theological tradition, that would seem to require a person whose immediate awareness is not limited to the now, who is always already perfect and so could 'only go downhill' were $\mathrm{He}$ to be in time, and who cannot even be conceived to have parts (cf. Metz 2013a: 87n6, 111-112). How, and even whether, that sort of being could create a physical universe remain genuine puzzles.

\section{INCOHERENCE IN SUPERNATURALISTS' BELIEFS?}

In the book I argue that those inclined to hold supernaturalism should not adopt it, since doing so would be in tension with claims they already hold, or at least sensibly should. Specifically, if they claim to know that meaning exists, as most supernaturalists do, and then if they also claim not to know that God exists (even if they have faith in God), as many do and should, then they would be contradicting themselves to claim to know that if meaning exists, then God exists, a principle implied by supernaturalism (2013a: 88-97, 145-146, 158-159). In the following, I unpack this tersely stated objection and consider how Cottingham and Wielenberg reply to it. ${ }^{6}$

In addition to this argument, which is directed against supernaturalists who claim to know that some meaning exists in our lives, in the final chapter of the book I develop another incoherence argument, against those supernaturalists who claim to know that there is no meaning in our lives (2013a: 240-246). Wielenberg is the only one to have yet noticed and replied to this argument, and I take up his replies at the end of this section.

Consider now those supernaturalists who think they know that there is some meaning in our lives. According to the core of my argument

${ }^{6}$ For additional critical discussion of this objection, see Waghorn (2015) but also Metz (2015a: 258-262). 
against them, ${ }^{7}$ there is a logical inconsistency in making the following three claims: (1) I know 'If X, then Y' is true; (2) I know X obtains; (3) I do not know whether Y obtains. Now, I maintain that most supernaturalists would be committed to an instantiation of the three claims. Specifically, for those who claim to know that meaning exists as well as that supernaturalism is true, it would be the case that they would then hold the following version of the three claims: $\left(1^{*}\right)$ I know 'If meaning exists, then God exists' is true; $\left(2^{\star}\right)$ I know meaning exists; $\left(3^{\star}\right)$ I do not know whether God exists. My contentions are that supernaturalists must drop one of these claims to avoid contradiction and, specifically, that they ought to drop $\left(1^{\star}\right)$, the God-based theory of life's meaning, since $\left(2^{*}\right)$ and $\left(3^{\star}\right)$ are much more defensible.

$\left(1^{\star}\right)$ is the claim that one has enough epistemic reason for knowledge of a God-based theory of meaning in life. $\left(2^{\star}\right)$ is the default position of most philosophers, including supernaturalists, working in the field of meaning in life; a large majority reject scepticism and nihilism when it comes to meaning in individual lives and for what they think is conclusive reason. For all we know, there was indeed meaning in the lives of people such as Mandela, Einstein and Picasso. And $\left(3^{*}\right)$ is the idea that, even if one has faith in God, or some epistemic reason to believe in Him, it is extremely difficult to maintain that one has enough epistemic reason to claim knowledge of His existence; many religious believers, even philosophical ones, deny that they know God exists, even if they elect to believe in Him anyway. One cannot consistently hold $\left(1^{\star}\right),\left(2^{\star}\right)$ and $\left(3^{\star}\right)$, and ought to jettison $\left(1^{\star}\right)$.

In the book I deploy this kind of argument not merely against supernaturalism, but also, as Cottingham and Wielenberg note, against an argument for (a version of) it, namely, an appeal to the divine command theory of morality. Cottingham, for instance, has argued in his work that God is the source of meaning in life, since only He could create the kind of moral system that would confer meaning on our lives upon living up to it (2005: 37-57). I contend, however, that there is also a kind of incoherence in this position, insofar as Cottingham claims to know that some acts are right and some are wrong (2005: esp. 55) but also not to know that God exists (2003: esp. 6-8, 18, 61-62, 92). Those two claims are logically incompatible with the assertion of the divine

${ }^{7}$ Here I borrow from a recent restatement of the argument in Metz (2015a: 258). 
command theory, which implies that if rightness or wrongness exists, then God exists.

Cottingham now replies to this argumentative strategy in two major ways, going beyond earlier statements, and it is a pleasure to continue a debate with him that began in $2008 .{ }^{8}$ First, at one point he appears to deny claiming to know that God is the basis of moral requirements and hence of meaning in life. He points out, sensibly, that, for any statement of the form 'If X, then Y', it can be coherent to believe that both $\mathrm{X}$ and $\mathrm{Y}$ obtain even if the evidence for the existence of $\mathrm{X}$ is not 'as strong as the evidence' of Y (Cottingham 2016: 51-52). I accept that point in the book, and work to clarify that an incoherence most clearly obtains if the discrepancy between the amount of evidence is stark, for instance to the point where one claims to have enough evidence for knowledge of $\mathrm{X}$ but not enough evidence for knowledge of Y (2013a: 96-97). At this point in the dialectic, Cottingham says, 'The point seems to be that my claim that God is the basis of moral requirements must be a claim to conclusive knowledge, but I am unclear as to why my position has to be formulated in this epistemically maximal way' (2016: 51).

I do not use the phrase 'conclusive knowledge', and do not intend to appeal to any sort of epistemic maximum when maintaining that there is an incoherence in the beliefs of many supernaturalists. Rather, in the book I sometimes speak of 'conclusive evidence', which I define as evidence sufficient for a claim to knowledge (2013a: 97). The incoherence argument is that one cannot coherently claim to know that some acts are morally required (or meaningful), to know that if some acts are morally required (or meaningful), then God exists, but, further, not to know whether God exists. Cottingham appears to make all three claims, and many others would be committed to all three were they to accept the divine command theory (or supernaturalism). My suggestion is that they reject the latter, to avoid the incoherence.

Perhaps Cottingham is denying a claim to know that if some acts are morally required (or meaningful), then God exists. That is an avenue that Nicholas Waghorn (2015: 153) has suggested Cottingham could take. However, the cost of doing so is obvious, namely, forsaking

${ }^{8}$ For my initial statement, see Metz (2008), and for Cottingham's initial reply, which required me to tighten up the argument as (usually) presented in Meaning in Life, see Cottingham (2008: 264-268). 
a philosophical defence of the divine command theory of morality and a God-based account of what would make a life meaningful.

Cottingham's other reply concerns not the claim $\left(1^{*}\right)$ I know 'If meaning exists, then God exists' is true, but rather $\left(3^{*}\right)$ I do not know whether God exists. Cottingham suggests that there are ways of knowing that God is real that he rightly suspects I do not accept. Whereas in Cottingham's first book on what makes a life meaningful (2003), it looked as though he did not believe he could know that God exists, in his present discussion Cottingham speaks of 'understanding' and 'apprehending' the theistic nature of reality, and in an 'authoritative' way through 'emotional and imaginative modes of awareness' and, in particular, through 'religious experiences' (2016: 52). Cottingham and other supernaturalists could indeed avoid the incoherence if they had good grounds for claiming to know that God exists.

And so the key question becomes: do they? That is a mighty big question, one I am not going to be able to settle in this reply to five critics of various facets of my book on life's meaning. I merely note that, as I briefly mention in the book, an appeal to religious experience most promises to ground knowledge of God when the phenomenologies of those who have them are similar, or at least not radically different (Metz 2013a: 90n8). However, Christians tend to report experiencing a world of beauty that has its source in a spiritual person with the three omniproperties, whereas many Hindus report experiencing the ultimate nature of reality as indivisible, without separate persons at all, many Confucians report experiencing the presence of an impersonal Heaven that imposes standards to which we must conform, and many indigenous African people report experiencing the presence of ancestors (invisible persons who have survived the deaths of their bodies and continue to reside on earth) through whom alone a human being has any ability to learn about God. The best explanation of such radical difference, I submit, is that religious experiences are not reliable guides to what exists independent of us.

In reply to this point, Cottingham draws a fascinating analogy with knowledge of music.

Complex training and transformation in the subject are required for the relevant musical properties to be discerned. And hence the evidence may be neither widely available nor uniform across different groups; but the apprehension of the properties in question, when it does occur, 
may nonetheless reasonably be considered authentic and authoritative (Cottingham 2016: 52).

Applied to the religious case, the claim would have to be something like Hindus, Confucians and Africans simply have not had 'the right kind of receptivity' (Cottingham 2016: 52), given Cottingham's commitment to Christianity. They have not been primed to detect the evidence of monotheism.

The natural question to pose is what reason there is to think that the Christians, or any particular religious groups, are having the veridical religious experiences, as opposed to the others. In order to know which phenomenologies are more accurate than others, it appears necessary to go beyond them, and, in particular, to go back to appealing to what Cottingham calls 'spectator evidence' (2016: 52), which I find most compelling when seeking to apprehend the nature of the external world, namely, consideration of which perspectives best facilitate prediction of future events, control over which events occur, and explanation of comparatively uncontested data.

Another concern I have is about the strength of the analogy. It is true that those trained in tonal, Western music will initially have trouble comprehending, let alone appreciating, other styles of music, such as Indian raags or the atonal music of, say, Anton Webern. However, with enough exposure and attention, often the experts are able to agree to a large extent about what they are hearing and whether it is musically important (even if what they like continues to differ). I doubt that a similar sort of convergence in judgment is forthcoming amongst religious people. Hindus are not likely to come to see the world as having sprung from a person, just as Christians are unlikely to come to see the world as an indivisible unity that is devoid of separate persons, even upon acquaintance with the opposing perspective.

I am sure that Cottingham would have revealing things to say in what I hope will be another stage of debate between us. Like Cottingham, upon carefully and accurately presenting my charges of incoherence, Wielenberg also argues that divine command theorists of morality and supernaturalists about meaning can best avoid them by rejecting the claim that they do not know that God exists. However, his rationale differs from Cottingham's. Wielenberg contends that supernaturalists who initially did not know that God exists might now plausibly claim to know that God exists, precisely in light of knowing that a God-based 
account of meaning is true and that meaning exists (2016: 29).

Others have suggested this manoeuvre (Roger Crisp cited in Metz 2013a: 97n17; and Waghorn 2015: 159-160), and my replies to them still seem strong to me (Metz 2013a: 97n17, 2015a: 260-261). In a nutshell, I contend that such a move is unpromising, since it is the God-based account of meaning that is in question. In the context of debate about life's meaning, it is a highly contested supernaturalist theory in need of philosophical defence, not a stable premise to be used to draw a conclusion about the existence of God.

Outside of debate about which theory of life's meaning is most justified, and when seeking to decide matters with real rigour, it would be apt to weigh up all the available evidence for and against the relevant claims, which include the assertions of supernaturalism and theism. However, I would be content to have shown that Cottingham and other supernaturalists must choose between the three claims of knowing that if meaning (or rightness) exists, then God exists, of knowing that meaning (rightness) exists, and of not knowing that God exists, and to have noted that, on balance at the moment, philosophical opinion counsels letting go of the first claim.

The incoherence argument just discussed applies only to those supernaturalists who claim to know that some lives have meaning in them. However, not all supernaturalists do, for some are atheists who hold that while meaning requires God to exist, God does not exist. As Wielenberg aptly sums up, 'supernaturalism + atheism = nihilism' (2016: 32 ), the view that all lives are meaningless. I also present an argument in the book meant to show that those who hold this combination of views suffer from a kind of incoherence amongst their beliefs.

Specifically, I argue that, probably, if atheism is true, then supernaturalism is false. If atheism is true, then humanity's deepest value judgments have not come from God but instead are a product of natural selection, i.e., are ones that helped us to survive and to flourish. Which kinds of judgments would have been likely to have helped us do so?

Cooperation, or any other action of the sort that would have enabled our ancestors' genes to be passed on, would not have done so had it been predicated on facts about a maximally conceivable ideal that could obtain only in a spiritual realm, which the friend of the present argument for nihilism asserts does not exist. Early members of Homo sapiens would not have judged their own or others' behaviour in light of standards that, 
ex hypothesi, could never be fulfilled. They would not have judged their lives to be worthy of great esteem in light of a state of perfection that is non-existent (Metz 2013a: 244).

Instead, the kinds of value judgments that would have helped us to survive and flourish, I contend, are ones appealing to imperfect standards that could be satisfied by earthly lives' (Metz 2013a: 244) such as naturalist conceptions of meaning.

Wielenberg offers two replies to this argument against supernaturalists who are nihilists. First, he suggests that 'our ancestors might have judged behaviour in light of unfulfillable standards if they had mistakenly believed that such standards could be fulfilled, and Metz provides no reason to rule out that possibility' (2016: 33).

In response, note that the historical record strongly indicates that monotheism, and more generally the appeal to spiritual idealization, is a recent phenomenon. For all we can tell, it began no more than 6,000 to 10,000 years ago, with the rise of a division of labour, agriculture, writing systems and the like, whereas humanity has been around for millions of years. It is possible that early hominids had images of perfection that guided their interaction and that they mistakenly believed they could reach or approximate it. However, it is unlikely that such a conceptual repertoire had been developed prior to the advent of 'civilization'.

Wielenberg's deeper reply is that the logic of my argument misfires, and does not reach its target of supernaturalism. According to him, it provides merely an explanation of why people would not believe supernaturalism, but does not provide a reason to believe that this view is unwarranted. 'Metz's reasoning yields at most the conclusion that atheism implies that humans will in fact not accept supernaturalism, but the conclusion he is aiming for is that we lack justification for accepting supernaturalism' (2016: 33).

In fact, I think I am entitled to the stronger, and more relevant, claim. For one way to see this, turn away from what talk of 'meaningful' would have connoted to our ancestors, and instead consider what it would have denoted, i.e., picked out in the world. Suppose that some variant of the causal theory of reference is true of value terms. If atheism were also true, so that there is no spiritual dimension, as is the case by the present version of supernaturalism I am seeking to rebut, then when our ancestors used terms such as 'meaningful', they could have referred only to physical properties. The extension of the word 'meaningful' would 
have to have been constituted by certain patterns of being and doing in the natural world. Just as the extension of the word 'water' is stuff made up of a certain chemical composition, such that water just is $\mathrm{H}_{2} 0$, so what counts as meaningful for us would be constituted by certain natural facts alone. But that implies the falsity of supernaturalism.

At the end of his contribution, Wielenberg draws on certain claims in my book to usefully reconstruct what he considers to be a more powerful objection to supernaturalism. Since it appeals to my substantive theoretical account of which properties constitute meaning in a life, I address it only after defending that view from objections, in the following section.

\section{IS MEANING FUNDAMENTAL?}

In posing the question of this heading, I have two things in mind. One is whether meaningfulness is a basic value, one that is distinct from happiness, hedonistically construed as pleasure. Another is whether, if it is, its content (at least when it is particularly great) is well captured by (partial) appeal to fundamental facts about human existence, those responsible for, or that explain, much else about it in a given domain.

Goetz provides reason to doubt both, maintaining that meaning is identical to happiness qua pleasant experiences. I address Goetz's position first, before tackling counterexamples that he and Goldschmidt have advanced against the fundamentality theory of the nature of meaningfulness.

As Goetz points out, I hold the view that it is logically contradictory to think that meaning is exhausted by pleasure (Metz 2013a: 27). That is, I maintain that what talk of 'meaning' connotes, at least to a large majority of philosophers, is a higher intrinsic good other than any experience that feels good. Setting that strong view aside, however, I still spend a lot of time in the book arguing that there are many respects in which meaning and pleasure are distinct goods. For example, I provide putative examples of unhappy or unpleasant meaningfulness as well as of meaningless happiness or pleasure (2013a: 5). I provide analyses of the concepts of meaning and pleasure, pointing out that they connote different ideas (2013a: 60-61). And I suggest several substantive, valuetheoretic differences between the two, for instance with regard to which kind of attitude is appropriate to take towards them, whether they can be realized posthumously, and when they are to be preferred in a life (2013a: 65-74). Goetz is an informed and careful interlocutor; how can 
he and I have such extremely divergent views about what would make a life meaningful?

My suspicion is that Goetz and I are talking past one another. What he means by the word 'meaningful' differs from what I mean by it. Crucially, for Goetz, when posing the question of what makes a life meaningful he is at 'the most basic' level asking the question, 'What, if anything, makes life worth living?' (2016: 45). I, however, believe that the meaningful and the worthwhile are distinct (even if somewhat overlapping) properties, where pleasure can invariably make life worth living but cannot, in itself, make life meaningful. I did not argue that point in Meaning in Life, but did elsewhere soon after I had submitted the manuscript to the press (Metz 2012, 2014: 102-103).

In these latter texts, I suggest, for example, that a person's life could be more meaningful if she voluntarily underwent a life that were not worthwhile so that others would not have to undergo the same fate (vide Mandela having spent 27 years in prison). If such a thought experiment is coherent, then the meaningful and the worthwhile are indeed distinct!

Another reason for thinking that the meaningful is not reducible to, or even centrally captured by, the worthwhile concerns the reasonableness of suicide. Take a classic lifeboat scenario where there are not enough seats for all those who need them, and where you volunteer to give yours to someone else. This could well be a meaningful action on your part, but it is one that makes your life worth ending, not one that makes it worth living.

A third reason I proffer for divorcing the meaningful from the worthwhile is the availability of posthumous meaning. It is plausible to think that van Gogh's life was made more meaningful by the recognition and appreciation his paintings received after his death, but implausible to think that the latter made his tormented life any more worthwhile, especially when worthwhileness is deemed to be exhausted by pleasure.

Given these and other arguments, my view is that Goetz advances a prima facie plausible account of what makes a life worth living, ${ }^{9}$ but not so attractive a view of what makes it meaningful. My hope is that these considerations provide additional reason, beyond the intuitions and other arguments in the book, for denying that a meaningful life just is a pleasant one.

9 Albeit not one that I hold since I think there are objective goods that enhance worthwhileness - meaningfulness being one of them! 
Even if Goetz is incorrect that a life is meaningful merely insofar as it is pleasurable, his objections to my alternative, fundamentality theory could still be correct. He maintains that it posits an overly intellectual and unattainable standard for most people. However, these characterizations are based on misinterpretations of the view, ones that I unfortunately did not do enough to forestall in the book (cf. Kershnar 2014, who voices similar concerns).

I maintain that the meaning in a life is in the first instance a function of the development and exercise of one's rational nature, where the latter includes attitudes such as emotions, insofar as these are responsive to judgment. Using one's intellectual, emotional and others forms of intelligence in sophisticated, robust ways (and without violating certain moral constraints), perhaps merely to play games, can confer some meaning on one's life.

However, noteworthy meaning comes from contouring one's intelligence towards a particular kind of object, namely, one fundamental to human existence in some way, and doing so in a successful manner. By a fundamental object I mean a fact or property that that is causally or explanatorily responsible for much else in a given domain. For example, in the book I spoke of reasoning and relating as conditions fundamental to the course of a typical human life; they account for much of its direction. I also addressed reproduction, labour, neurosis, communication, religion, love and natural selection as conditions fundamental to the course of a human society. The standard conceptual categories used in biology, psychology and sociology pick out properties that are responsible for much of how a given society functions or how the human species has developed. In addition, I characterized knowing about space-time, gravity and causation as about conditions fundamental to the human environment. And in more recent work (Metz 2014: 104106), I have contended that coming to know and support the character of a particular human person, i.e., what makes her tick, as opposed to her more surface properties such as her appearance, would be a particularly meaningful enterprise.

In sum, substantial meaning consists of orienting one's rational nature in a complex, willful and positive way towards such kinds of fundamentality, and by making some kind of advance with regard to the latter, sometimes by discovering fundamental facts, other times by protecting them, and still other times by expressing respect for them. For example, when it comes to the good, Mandela and Mother Teresa 
had superlative meaning in their lives because they greatly supported people's abilities to reason and to relate, properties that are responsible for much of a characteristic life. With respect to the true, Darwin and Einstein discovered facts that account for much about human nature and humanity's environment (respectively), where that important knowledge conferred importance on their lives. And regarding the beautiful, Picasso's Guernica and Dostoyevsky's Brothers Karamazov were significant, making their lives such, because they creatively addressed themes such as war and morality that determine much of our social interaction.

In the book I focused on exemplars of meaning in life, and so discussed greats such as Mandela, Einstein, etc. I can see why, in light of such recurrent illustrations, Goetz would worry about 'unattainability', about expecting too much of people for them to count as having lived meaningfully. However, my strategy was to start with the clearest instances of meaningfulness and then to 'work my way down' to more everyday lives. I mentioned the latter at times in the book (e.g., 2013a: $216,226,228,230)$, but it was admittedly not the dominant motif. Let me do a bit to clarify now.

Although meaning of the sort that really stands out involves (1) sophisticated and robust rationality that is (2) contoured towards fundamental facts about human beings and (3) successfully makes some kind of large advance in that respect, more everyday kinds of meaning need not involve all three, or, in fact, any of the three. Sophistication and robustness are matters of degree, and so somewhat less complex and willful exercises of reason could confer some meaning, simply in themselves, apart from the importance of the object towards which they could be directed; vide the example above of playing games. More meaning would come if a person's intelligence were positively directed towards the right sort of object, a fundamental one, but instead of contouring it towards what is fundamental to humanity in some way, as per Darwin, one might do so towards what is fundamental to a particular person, say, the character of one's spouse. And then some meaning can come from merely trying to help, learn or create, even if one fails to do so in ways that reach their target, let alone in ways that make major advances with regard to them.

Another concern that Goetz has about the fundamentality theory is 'intellectualism', as he thinks that for me, 'what meaning in life essentially comes down to is orienting one's reason toward understanding the explanations of things in the realms of the true, the good, and the 
beautiful' (2016: 44). This, however, is not my view. One way, but not the only way, of acquiring meaning in life is by discovering or understanding fundamental facts, ones that explain much else about a human domain. Another way of doing so is by supporting them, e.g., when one enables people to reason and to relate, or when one cares for the fundamental dispositions of one's beloved. Yet another way of doing so is by creating a work of art that is about some dimension of humanity that is responsible for much else about the course of our lives, e.g., love, beauty, neurosis, loneliness, loss. Furthermore, as I have said above, it is only substantial meaning, not meaning as such, that I maintain requires engagement with fundamentality.

Goldschmidt is also unclear about the implications of the fundamentality theory, and wonders about their plausibility to the extent he can tease them out. He questions what this view entails for the meaningfulness of engaging in rituals, on the one hand, and for the meaningfulness of our lives on the supposition that there would be no future generations, on the other (2016: 22-24).

The first case, regarding rituals, is meant to be one in which there is not engagement with either the good, the true or the beautiful, but in which there is intuitively meaning. ${ }^{10}$ More specifically, Goldschmidt imagines that neither God nor morality actually exists, and then considers whether religious rituals might still be meaning-conferring.

Goldschmidt helpfully offers one potential reply on my behalf, but I mention some others. For me, much depends on the nature of the ritual. If the ritual involves communion with other persons, there could well be a dimension of the good, i.e., participation and beneficence, that is meaningful, even if it were not imbued with moral value.

Another thought is that a ritual could be instrumentally valuable, meaningful as a means (as it were), even if it lacked meaning in itself. If engaging in the ritual helped one to step out of one's routine, to reconsider the path of one's life, and then to exercise one's reason in beneficent, reflective and creative ways in the future, that might adequately capture its intuitive worth.

Goldschmidt's second counterexample has the inverse structure of the first; it is one in which there is engagement with the good, the true and the beautiful, but in which there is intuitively little or no

${ }^{10}$ Kershnar (2014: 99-100) presents a similar sort of case, although, in hindsight, I see that I neglected to reply to the respect in which ritual was a part of it (in Metz 2014). 
meaning, since the human race is soon to die out. Drawing on Samuel Scheffler's influential conjectures (2013), Goldschmidt wonders whether a person, Sue, having oriented her rationality towards fundamentality, would have real meaning in her life if she were of the last generation of human beings; perhaps having some kind of influence on future human beings is necessary for meaning, or at least what one would describe as a 'meaningful life on balance', for Sue.

Once again, Goldschmidt resourcefully considers how I might plausibly reply to the concern, suggesting that 'the lasting good of Sue's deeds and the beauty of her paintings will be significantly reduced with the coming apocalypse' (2016: 23-24). That is indeed the sort of point I would make, and at times in the book I noted that meaning is in many cases available posthumously, in virtue of the 'ripples' one's life might have upon washing over others (2013a: 23, 50, 54, 130-131, 247-249). Although I am not a consequentialist, and so deny it is merely the longterm results of one's actions that constitute meaningfulness, I accept that they can enhance it (e.g., 2013a: 198, 221).

However, I would qualify this approach in some ways. For one, I do not believe that future generations are necessary for one's life to have meaning, perhaps even substantial meaning, in it. For example, much meaning could come from working to comfort others aware of the impending doom of the human race.

For another, insofar as I believe that future generations can affect the meaning of our lives, it is in fact usually not in virtue of one's influencing them causally. As I argue elsewhere, what best explains most of the sense we have that meaning would be lost were the human race to die out soon is not so much that we would no longer be able to do future generations any good, but rather, roughly, that we identify with the good that they would have done (Metz forthcoming).

In closing, I note an implication of the fundamentality theory that I am heartened that Wielenberg has highlighted and appreciated, and that I did not emphasize enough in the book. ${ }^{11}$ It is that one could view the fundamentality theory as common ground between a moderate kind of supernaturalist and the naturalist, and hence potentially as a way to resolve the debate between them. I maintain that substantial meaning in life comes from contouring one's rational nature towards conditions largely responsible for much else about human existence. It is an open,

${ }^{11}$ But that I have noted since then in Metz (2015b: 121-122), from which I crib here. 
metaphysical question what those conditions are. If God existed, then He would constitute fundamentality. As Wielenberg says, 'On theism, God is the fundamental condition of human life, so the fundamentality theory implies that if theism is true, then God is extremely relevant to whatever meaning human lives might have' (2016: 34). However, if instead atheism is true, then human lives could still be meaningful, in virtue of orienting their intelligence towards certain physical facts that causally or explanatorily account for much else about them. Although debate continues about what is fundamental to our lives, for all sides, perhaps upon reflection, fundamentality is what matters.

Acknowledgements. The introduction to this article has benefited from the input of Yujin Nagasawa.

\section{BIBLIOGRAPHY}

Affolter, Jacob. 2007. 'Human Nature as God's Purpose', Religious Studies, 43: 443-455

Cottingham, John. 2003. On the Meaning of Life (London: Routledge)

Cottingham, John. 2005. The Spiritual Dimension: Religion, Philosophy and Human Value (Cambridge: Cambridge University Press)

Cottingham, John. 2008. 'The Self, the Good Life and the Transcendent', in Nafsika Athanassoulis and Samantha Vice (eds), The Moral Life: Essays in Honour of John Cottingham (New York: Palgrave Macmillan), pp. 231-274

Cottingham, John. 2016. 'Theism and Meaning in Life', European Journal for Philosophy of Religion, 8: 47-58

Goetz, Stewart. 2016. 'In Defence of Supernatural Purpose Theory', European Journal for Philosophy of Religion, 8: 35-45

Goldschmidt, Tyron. 2016. 'The Meaning of Meaning: Comments on Metz's Meaning in Life, European Journal for Philosophy of Religion, 8: 19-25

Jech, Alexander. 2016. 'Pascal and the Voicelessness of Despair', European Journal for Philosophy of Religion, 8: 5-17

Kershnar, Stephen. 2014. 'Thad Metz's Fundamentality Theory of Meaning in Life: A Critical Review', Science, Religion and Culture, 1: 97-100

Metz, Thaddeus. 2000. 'Could God's Purpose Be the Source of Life's Meaning?', Religious Studies, 36: 293-313

Metz, Thaddeus. 2007. 'God's Purpose as Irrelevant to Life's Meaning: Reply to Affolter', Religious Studies, 43: 457-464

Metz, Thaddeus. 2008. 'God, Morality and the Meaning of Life', in Nafsika Athanassoulis and Samantha Vice (eds), The Moral Life: Essays in Honour of John Cottingham (New York: Palgrave Macmillan), pp. 201-227 
Metz, Thaddeus. 2012. 'The Meaningful and the Worthwhile: Clarifying the Relationships', The Philosophical Forum, 43: 435-448

Metz, Thaddeus. 2013a. Meaning in Life: An Analytic Study (Oxford: Oxford University Press)

Metz, Thaddeus. 2013b. 'How God Could Assign Us a Purpose without Disrespect: Reply to Salles', Quadranti - Rivista Internazionale di Filosofia Contemporanea, 1: 99-112

Metz, Thaddeus. 2014. 'Meaning as a Distinct and Fundamental Value: Reply to Kershnar', Science, Religion and Culture, 1: 101-106

Metz, Thaddeus. 2015a. 'Assessing Lives, Capturing Naturalism, and Giving Supernaturalism Its Due: Reply to 13 Critics of Meaning in Life, in Masahiro Morioka (ed.), Reconsidering Meaning in Life (Saitama, Japan: Waseda University), pp. 228-278

Metz, Thaddues. 2015b. 'Fundamental Conditions of Human Existence as the Ground of Life's Meaning: Reply to Landau', Religious Studies, 51: 111-123

Metz, Thaddeus. 2016. 'Is Life's Meaning Ultimately Unthinkable?: Guy BennettHunter on the Ineffable, Philosophia, DOI 10.1007/s11406-015-9654-y

Metz, Thaddeus. Forthcoming. 'Reasons of Meaning to Abhor the End of the Human Race, Faith and Philosophy

Poettcker, Jason. 2015. 'Defending the Purpose Theory of Meaning in Life', in Masahiro Morioka (ed.), Reconsidering Meaning in Life (Saitama, Japan: Waseda University), pp. 180-207

Scheffler, Samuel. 2013. 'Death and the Afterlife', in Niko Kolodny (ed.), Death and the Afterlife (Oxford: Oxford University Press), pp. 15-110

Swinburne, Richard. 2016. 'How God Makes Life a Lot More Meaningful', in Joshua Seachris and Stewart Goetz (eds), God and Meaning: New Essays (New York: Bloomsbury Academic), ch. 8

Waghorn, Nicholas. 2015. 'Metz' Incoherence Objection: Some Epistemological Considerations', in Masahiro Morioka (ed.), Reconsidering Meaning in Life (Saitama, Japan: Waseda University), pp. 150-168

Wielenberg, Erik. 2016. 'Metz's Case against Supernaturalism', European Journal for Philosophy of Religion, 8: 27-34

Yamaguchi, Sho. 2015. 'Agreement and Sympathy: On Metz's Meaning in Life, in Masahiro Morioka (ed.), Reconsidering Meaning in Life (Saitama, Japan: Waseda University), pp. 66-89 